increased odds ratio $(\mathrm{OR})$ of diseases including diabetes $(\mathrm{OR}=$ $1.42, \mathrm{p}<0.001)$, hypertensive disease $(\mathrm{OR}=1.22, \mathrm{p}<0.001)$, ischaemic heart disease $(\mathrm{OR}=1.12, \mathrm{p}<0.001)$ and organic mental disorder $(\mathrm{OR}=1.77, \mathrm{p}<0.001)$.

Discussion Using the largest accelerometry cohort to date, 6-8 hours of sleep along with non-fragmented sleep was associated with better, future metabolic and mental health. However, sleep duration and quality alone were not sufficiently sensitive or specific to be a stand-alone biomarker for future health status. Future studies should consider additional lifestyle and health factors.

\section{COMPARING THE SUBJECTIVE SLEEPINESS AND SOCIAL HEALTH OF HIGHER EDUCATION STUDENTS ALONGSIDE A NON-STUDENT SAMPLE}

Katrina Burrows*, Abbie Millett. University of Suffolk

\subsection{6/bmjresp-2021-bssconf.4}

Introduction This paper will evaluate the difference between Sleepiness, Loneliness and Social Connectedness between a higher education and mundane sample. Although current literature evaluates the role of Sleepiness within Higher education (Araújo et al, 2021), to the best of our knowledge there are no papers comparing a student population to a non-student sample.

A significant difference between the subjective sleepiness scores of a student and non-student population is expected, which would demonstrate that a student sample perceive themselves to be sleepier than their non-student counterparts.

Methods An online survey was administered to 202 participants via Qualtrics. 94 were non-students and 108 were higher education students. Sleepiness was measured using the Stanford Sleepiness Scale (Shahid et al, 2011), The UCLA Loneliness Scale was used to measure loneliness (Russell, 1980).

Results An independent t-test showed that there was a significant difference between students and non-students subjective sleepiness scores. $(\mathrm{t}(200)=2.23, \mathrm{p}=0.02)$ with students being significantly more like to rate themselves higher on the Stanford Sleepiness Scale. (Figure 1).

Further analysis shows that Loneliness and Subjective Sleepiness are significantly correlated for a student sample ( $\mathrm{r}$ (108) $=0.308, \mathrm{P}=0.001$ ).

Discussion This study suggests that students enrolled within higher education are more highly associated with the risks of

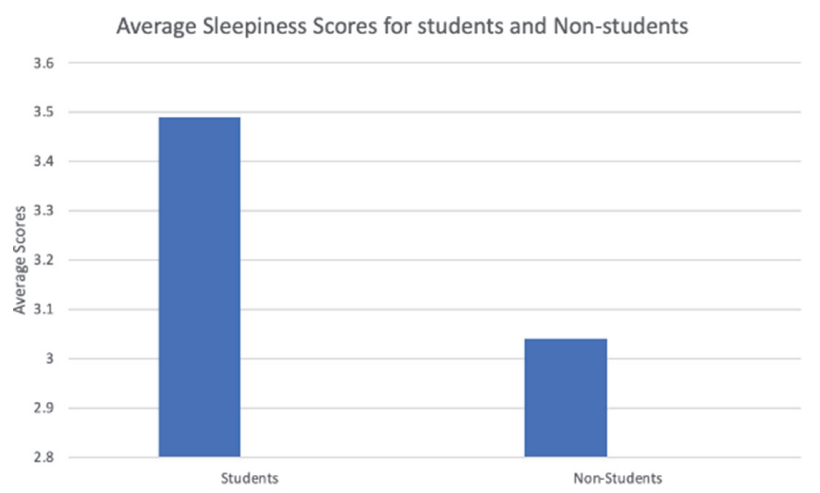

Abstract 4 Figure 1 Demonstrates the average Sleepiness scores for students and non-students
Excessive daytime Sleepiness and the resultant detrimental effects on social health. Further research needs to be performed to determine the negative effects of Sleepiness on Student's social health.

\section{INVESTIGATING METHODS OF SHARING INFORMATION TO SUPPORT ADOLESCENT SLEEP ISSUES DURING COVID-19}

Vicki Dawson*, Lisa Artis. The Sleep Charity, Doncaster, UK

\subsection{6/bmjresp-2021-bssconf.5}

Introduction Many studies outline adolescents are particularly at risk of developing sleep issues, experiencing delayed sleep onset. The aim of our study was to identify effective ways to support young people to improve sleep patterns using behavioural intervention during Covid-19 by promoting youth participation and sharing information at scale.

Method The study entailed recruiting young people with lived experience of sleep issues to create three distinct advisory boards. Through consultation it was established that Covid-19 was having a significant impact on sleep patterns in this cohort and there was an urgent need to create accessible, evidence-based sleep intervention. We established a website dedicated to sharing sleep education. A downloadable e-Book, live web chat, videos, a newsletter and resources for schools and parents were all created with the input of the boards.

Results The website launched on 1st October 2020 with the aim to reach 400 young people by the end of the project on 6 th June 2021. The project had the following reach:

Website visitors - 19,766

eBook downloads - 33,468

Newsletter signups - 1,601

Video views sharing sleep tips - 14,491

Young people receiving direct support through live chat -34

Schools receiving resource pack $-3,500$

Feedback from 50 individuals was evaluated to inform future work around the eBook and it was established that there is a strong preference for printed material, these findings were also supported by our youth advisory board.

Discussion Young people consistently told us that they want to be able to access evidence-based sleep information to support their own sleep patterns, our work lays important foundations on which to build nationally to support adolescent sleep and wellbeing at scale.

\section{EVALUATION OF A ONE-TO-ONE SLEEP SERVICE DELIVERED VIA ONLINE CLINICS BY COMMUNITY SLEEP PRACTITIONERS IN THE UK}

${ }^{1}$ Victoria Dawson*, ${ }^{2}$ Heather Elphick, 'Lisa Artis, ${ }^{2}$ Lowri Thomas, ${ }^{1}$ Claire Earley, ${ }^{1}$ Karen Tyas. ${ }^{1}$ The Sleep Charity, Doncaster, UK; ${ }^{2}$ Sheffield Children's Hospital, Sheffield, UK

\subsection{6/bmjresp-2021-bssconf.6}

Introduction Poor sleep is associated with many adverse outcomes in childhood. The most common sleep difficulty experienced by children is behavioural insomnia which responds to behavioural therapy. The Coronavirus disease 2019 (COVID19) global pandemic in 2020 has had a profound effect on children's sleep patterns. This project aimed to evaluate a one- 